\title{
Kinesiotaping versus Acupressure in Treatment of Postnatal Low Back Pain
}

\author{
MAHMOUD A. MAHMOUD, M.Sc.*; HALA M. HANAFY, Ph.D.**; WAFAA M. KAMAL, Ph.D.** and \\ MOHAMMED F. ABO-ELENIEN, M.D.***
}

The Department of Physical Therapy for Gynecology \& Obstetrics, New Cairo Police Hospital, Ministry of Interior* and Faculty of Physical Therapy, Cairo University** and Department of Gynecology \& Obstetrics, Om Elmasryeen General Hospital, Ministry of Health***, Egypt

\begin{abstract}
Background: Back pain was a dull ache starting soon after delivery and made worse by effort and relieved by rest. Examination showed only mild tenderness over the lumbar vertebrae. Other women had postural backache combined with pain over the sacroiliac joints. This pain was worse after sitting for long periods.
\end{abstract}

Aim of Study: The aim of this study was to compare between kinesio tape and acupressure in treatment of postnatal low back pain

Patients and Methods: This study was conducted on thirty women suffering from post natal low back pain (fifteen days after labor to ensure complete involution of uterus), their age ranged from 20-35 years and their body mass index not exceeding $30 \mathrm{Kg} / \mathrm{m}^{2}$. The women were randomly selected from outpatient clinic of obstetrics and gynecology in New Cairo Police Hospital and Madinet Nasr Police Hospital. They were randomly assigned into two equal groups: Group A (kinesio tape group) 15 women and Group B (acupressure group) 15 women. Group A: They had kinesiotaping on their back upwards from S2 to L1, three times per week for 4 weeks, the tape lasts on the skin till the next session and removed two hours before the new session. Group B: They received acupressure therapy by both thumbs at a rate of one minute pressure followed by one minute relaxation, on four points (B22, B23, B25, B27) at lumbar region, three times for each point, three times per week for 4 weeks. The session lasts for 24 minutes. All women were evaluated for pain severity using visual analogue scale (VAS) and lumbar mobility using tape measurement immediately before participation in the study and after end of treatment program (4 weeks)

Results: There were statistically significant decrease in pain severity and increase in lumbar range of motion in favor to group A when compared with group B.

Conclusion: It can be concluded that taping-in comparison to acupressure - is amore effective physiotherapeutic modality for treating postnatal low back pain.

Correspondence to: Dr. Mahmoud A. Mahmoud, The Department of Physical Therapy for Gynecology \& Obstetrics, New Cairo Police Hospital, Ministry of Interior
Key Words: Kinesio taping - Acupressure - Postnatal low back pain.

\section{Introduction}

POSTNATAL period or postpartum period is a period beginning immediately after the birth of a child and extending for about six weeks. Less frequently used are the terms puerperium or puerperal period [1].

Common postnatal problems include exhaustion, backache, sexual problems, perineal pain, urinary incontinence, fecal incontinence and depression [2] . During and after pregnancy, women often have pain in the pelvic girdle and/or the lower back [3]. Back pain in pregnancy is a substantial problem because it can persist into the post-partum period and thereby influence the postpartum recovery [4]

Back pain was a dull ache starting soon after delivery and made worse by effort and relieved by rest. Examination showed only mild tenderness over the lumbar vertebrae. Other women had postural backache combined with pain over the sacroiliac joints. This pain was worse after sitting for long periods. Some women had tenderness over the site of epidural insertion in addition to postural backache. On each occasion the pain had been participated precipitated by lifting the baby. The pain which radiated down in both legs was severe enough to force the woman to lie flat and rest [5]

Several pathophysiological causes have been suggested, such as laxity of ligamentous structures in the spine and pelvis due to relaxin, direct pressure on the lumbosacral nerve roots due to the increased dimensions of the uterus, muscular fatigue, referred 
pain, and pull or pressure on structures of the musculoskeletal system. Various causes of back pain seem to exist during pregnancy associated with problems after delivery such as persistent back pain [6].

Postpartum back pain has several other causes, one of which has been stated is epidural analgesia during labor [7]. Neurological complications of local and regional anesthesia, headache and low backache are common following spinal or epidural anesthesia [8]. Women who had epidural anesthesia were much more likely to suffer from subsequent newly occurring long term backache [9] .

Kinesio Taping is rehabilitative technique used to facilitate the body's natural healing process while providing support and stability to muscles and joints, without restricting their range of motion. It is used in a variety of muscle-skeletal and neuromuscular problems. The elasticity of the strips is longitudinal while the waved adhesive allows normal mechanical functioning of the skin. Kinesio tape does not contain latex, drugs or chemical substances. It consists of $100 \%$ cotton fibers and is sensitive to temperature, water resistant [10].

According to the Kinesio Taping Method Manual, this traction promotes an elevation of the epidermis and reduces pressure on the mechanoreceptors located below the dermis, thereby reducing nociceptive stimuli [11].

Acupressure is a manual approach that can be used for self-management of LBP. Acupressure, one of the Traditional Chinese Medicine (TCM) approaches, is a non-invasive manual approach that involves manipulation of the skin and soft tissues with primarily the fingertips instead of needles on acupoints, but it is less well studied than acupuncture [12].

\section{Patients and Methods}

We performed this study in outpatient clinic of obstetrics and gynecology in New Cairo Police Hospital and Madinet Nasr Police Hospital from $1 / 11 / 2019$ to $30 / 11 / 2019$.

Thirty women suffering from post natal low back pain (fifteen days after labor to ensure complete involution of uterus), their age ranged from 20-35 years and their body mass index not exceeding $30 \mathrm{Kg} / \mathrm{m}^{2}$. The women were randomly selected from outpatient clinic of obstetrics and gynecology in New Cairo Police Hospital and Madinet Nasr Police Hospital. They were randomly assigned into two equal groups; Group A (kinesio tape group) 15 women and Group B (acupressure group) 15 women.

Group A: This group consisted of 15 women with postnatal low back pain (fifteen days after labor to ensure complete involution of uterus). They had kinesiotaping on their back upwards from S2 to L1 three times per week for 4 weeks, the tape lasts on the skin till the next session and removed two hours before the new session.

Group B: This group consisted of 15 women with postnatal low back pain (fifteen days after labor to ensure complete involution of uterus). They received acupressure therapy by both thumbs at a rate of minute pressure followed by one minute relaxation, on the point on the surface of the skin for both bilateral points of the following four points (B22, B23, B25, B27), three times for each point, three times per week for 4 weeks. The session lasts for 24 minutes.

\section{Inclusive criteria:}

1- Their ages ranged from 20 to 35 years old.

2- There body mass index (BMI) not exceeding $30 \mathrm{~kg} / \mathrm{m}^{2}$.

3- All women were diagnosed by the physician as postpartum low back pain.

\section{Exclusion criteria:}

1- Spinal fracture or any other neurological disorders.

2- Lumbar disc herniation or degenerative disc disease

3- Lumbar spinal stenosis from lumbar disc herniation, degenerative joint disease, or spondylolisthesis.

4- Women with BMI exceed $30 \mathrm{~kg} / \mathrm{m}^{2}$.

5- Women who had polyneuropathy or other neurological disorders.

6- Skin disease interferes with kinesiotape or acupressure application.

Instrumentations:

\section{A- Instrumentations used for assessment:}

\section{1- Visual analogue scale (VAS):}

Visual analogue scale is $5 \mathrm{~cm}$ calibrated line with 0 (zero) representing no pain and 5 representing worst pain, used to assess the severity of pain before and after treatment for all patients in both groups (A\&B). Every woman of both groups $(\mathrm{A} \& \mathrm{~B})$ was asked to mark on the line that represents her level of pain before and after treatment. 


\section{2- Tape measurement:}

Used to assess range of motion of lumbar flexion, extension, right lateral bending and left lateral bending for all women in both groups (A\&B).

\section{B- Instrumentations used for treatment:}

\section{1- Kinesiotaping therapy:}

ARES taping made in Korea was used for treatment of women in group (A). Kinesio Tape has been designed to allow for a longitudinal stretch of $55-60 \%$ of its resting length. This degree of stretch approximates the elastic qualities of the human skin. The tape is not designed to stretch horizontally. The Kinesio Tape is applied to the paper substrate with approximately $25 \%$ of available tension. The average roll of Kinesio Tape size is $5 \mathrm{~cm} 5 \mathrm{~m}$ (2inx $16.4 \mathrm{ft})$ and it can stretch $35 \%$ from its resting length.

\section{2- Acu -point map:}

It was used for detecting the points and applying acupressure.

Assessment protocol:

All women were given a full explanation of the protocol of the study and consent form signed for each woman before participating in the study (Appendix I).

\section{1- Weight and height scale:}

Weight and height were measured for each woman in both groups $(\mathrm{A} \& \mathrm{~B})$ before treatment to calculate the body mass index (BMI) according to the following equation (Appendix II):

$$
\text { BMI }=\text { Weight }(\mathrm{Kg}) / \text { height }\left(\mathrm{m}^{2}\right) \text {. }
$$

\section{2- Visual analogue scale (VAS):}

Visual analogue scale is $5 \mathrm{~cm}$ calibrated line with 0 (zero) representing no pain and 5 representing worst pain, used to assess the severity of pain before and after treatment for all patients in both groups (A\&B). Every woman of both groups $(A \& B)$ was asked to mark on the line that represents her level of pain before and after treatment.

\section{3- Modified schober method:}

For measuring lumber mobility (lumber flexion, extension and side bending range of motion).

\section{I- Assessment of lumbar flexion:}

Modified Schober method was used to measure anterior flexion. The woman was asked to stand erect with her feet about shoulder-width apart. This position will stabilize the pelvis, aid woman in maintaining her balance, and help to increase the consistency of measurements. Then, the therapist stood behind the standing woman and determined the posterior superior iliac spines with both thumbs, and then an ink mark was drawn along the midline of the lumbar spines horizontal to the posterior superior iliac spines to mark the midpoint between the posterior superior iliac spines (PSIS). Then tape measure was used to identify and mark two points: one that is $10 \mathrm{~cm}$ superior to the midpoint between the posterior superior iliac spines (point A), then mark another point $5 \mathrm{~cm}$ inferior to the midpoint between the posterior superior iliac spines (point B). Then the therapist instructed the woman to bend over as far forward as she can and to keep her knees straight. When maximum anterior flexion was reached, the distance between points A and B was measured with the tape measure and recorded. Then 15 was subtracted from the last record (while bending forward). The increased distance along the tape was due only to flexion of the lumbar spine and is normally about $6-7 \mathrm{~cm}$ (less than $5 \mathrm{~cm}$ should be considered as abnormal). This test was performed for three consecutive times and the mean value was considered as lumber flexion range of motion. After each measurement, the woman was asked to return to the upright position.

\section{II- Assessment of lumbar extension:}

The therapist and the woman had the same positions as the previous assessment. The therapist marks the same points (A\&B). Then the therapist instructed the woman to bend backward into full lumbar extension and the new distance between the tow points $(\mathrm{A} \& \mathrm{~B})$ was measured in centimeters. Then the last record (while bending backward) was subtracted from 15 . This test was performed for three consecutive times and the mean value was considered as lumber extension range of motion.

\section{III- Assessment of lateral flexion:}

Each woman was asked to stand erect with her feet about shoulder-width apart. This position will stabilize the pelvis, aid woman in maintaining her balance, and help to increase the consistency of measurements. The distance was measured from the tip of the middle finger to the floor while standing erect (X1). The woman was instructed to move as far as possible into lateral flexion, the distance was measured from the tip of the middle finger to the floor (X2). Then X2 was subtracted from X1. Normal value of lateral spinal flexion was $16.2-28.0 \mathrm{~cm}$. This test was performed for three consecutive times and the mean value of each side was considered as lateral bending range of motion. 


\section{IV- Treatment protocol:}

\section{1- Kinesiotaping therapy:}

Kinesiotaping was applied three times/week for 4 weeks, the tape lasts on the skin till the next session and removed two hours before the new session for all women of group (A). ARES taping made in Korea. It was used for treatment of women of group (A). Every woman was instructed briefly and clearly about the nature of therapeutic kinesiotaping and its effect in order to gain their confidence and cooperation of all through the period of this study.

Every woman was asked to evacuate her bladder before starting the treatment session to be relaxed and then she was asked to assume a comfortable standing position. The treated area was swiped with cotton with alcohol to clean it prior to tape application, as skin should be free of oils and lotions then application of kinesio taping techniques [13].

Bilateral kinesio "I" strip for Para spinal muscles: Each woman was asked to flex her back and then the therapist applied the kinesio tape with the base of tape applied with no tension at the level of S2 and then applied very light to light tension (15-25\% of available tension). When the tail of the tape was approximately one to two inches from the end, the therapist stopped the tension and layed the end down without tension at the level of L1. Then the applied tape was rubbed to initiate glue adhesion prior to moving the muscle from its current stretched position [13].

The woman rested for twenty minutes after the tape application to gain full adhesive strength for the tape.

The women were instructed to remove the tape two hours before the next session that it is generally much easier to do when they had bathed or the tap was moist. It was best to remove from the top down. This would be in the direction of the body hair and should limit discomfort. Lift the tape from the skin, applying tension between the skin and the tape, and then push the skin away from the tape rather than pulling the tape away from the skin [13].

\section{2- Acupressure therapy:}

The treatment was applied three times per week for 4 weeks, the session lasts for 24 minutes for all women of group (B). Every woman was instructed briefly and clearly about the nature of acupressure therapy and its effect in order to gain her confidence and cooperation through the period of this study. Every woman was asked to evacuate her bladder before starting the treatment session to be relaxed and then she was asked to assume prone lying position. The session was performed by applying prolonged slow firm pressure by both thumbs at a rate of one minute pressure followed by one minute relaxation, on the point on the surface of the skin for both bilateral points of the following four points (B22, B23, B25, B27) (as they were the most common points for postnatal low back pain), three times for each point. The session lasts for 24 minutes.

\section{Statistical analysis:}

- Results are expressed as mean \pm standard deviation. Test of normality, Kolmogorov-Smirnov test, was used to measure the distribution of data measured pre-treatment.

- Accordingly, comparison between normally distributed variables in the two groups was performed using unpaired $t$ test. Analysis of covariance (ANOCA) test, was used to compare the post-treatment values of the two groups on controlling the effect of pre-treatment value. Bonferroni correction test was used to compare within group (pre-vs post-treatment) differences.

- In not normally distributed data, comparison between variables in the two groups was performed using Mann Whitney test. While comparison between pre- and post-treatment data in the same group was performed using Wilcoxon Sign Ranks test.

- Statistical Package for Social Sciences (SPSS) computer program (version 19 windows) was used for data analysis. $p$-value $\leq 0.05$ was considered significant.

\section{Results}

\section{- General characteristics:}

Table (1) showed the subject characteristics of both groups. There was no statistical significant difference in the mean age, weight, height and BMI between the two groups $(p<0.05)$ (Table 1 ; Figs. 1-4).

Table (1): Physical characteristics in the two studied groups.

\begin{tabular}{lcccc}
\hline & $\begin{array}{c}\text { Group A } \\
(\mathrm{n}=15)\end{array}$ & $\begin{array}{c}\text { Group B } \\
(\mathrm{n}=15)\end{array}$ & $t$-value & $p$-value \\
\hline Age (yrs.) & $28.67 \pm 2.61$ & $29.00 \pm 2.17$ & -0.380 & $0.707(\mathrm{NS})$ \\
Weight (kg.) & $68.50 \pm 1.54$ & $68.77 \pm 1.64$ & -0.460 & $0.649(\mathrm{NS})$ \\
Height (cm) & $1.66 \pm 0.04$ & $1.64 \pm 0.03$ & 1.658 & $0.108(\mathrm{NS})$ \\
BMI $\left(\mathrm{kg} / \mathrm{m}^{2}\right)$ & $24.91 \pm 0.80$ & $25.57 \pm 1.19$ & -1.774 & $0.087(\mathrm{NS})$ \\
\hline
\end{tabular}

Data are expressed as mean \pm SD

$\mathrm{NS}=p>0.05=$ Not significant. 


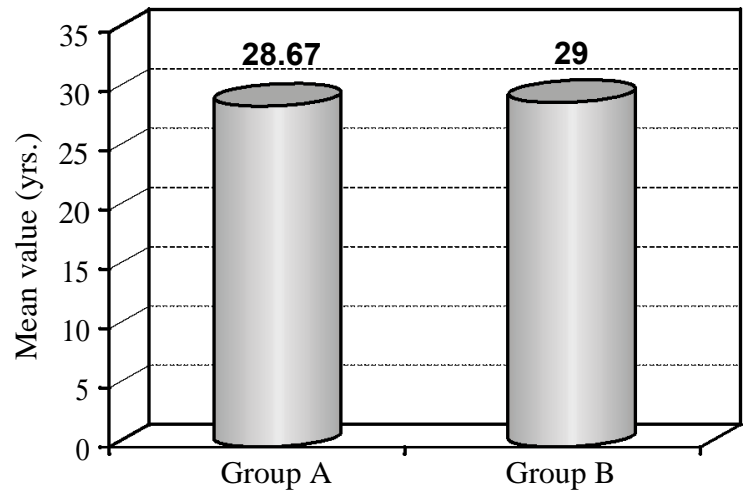

Fig. (1): Mean values of age in both groups.

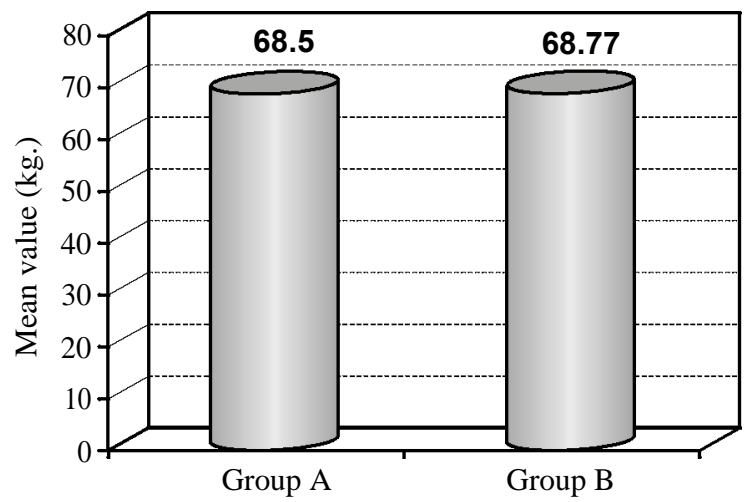

Fig. (2): Mean values of weight in both groups.

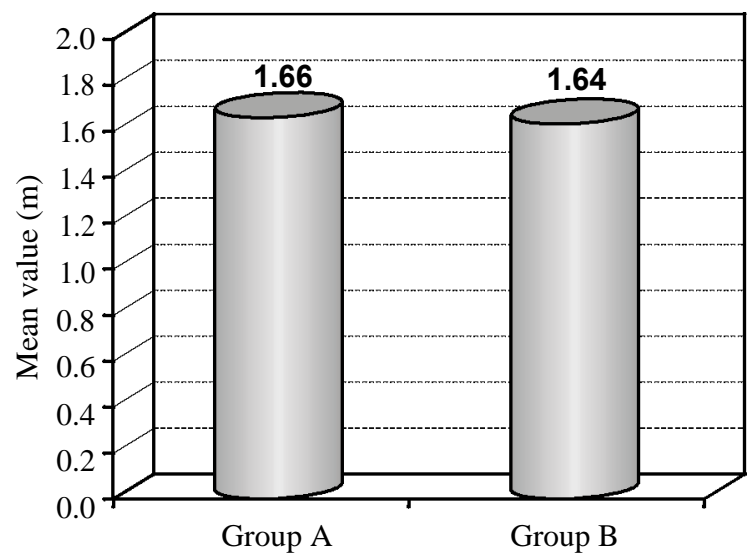

Fig. (3): Mean values of height in both groups.

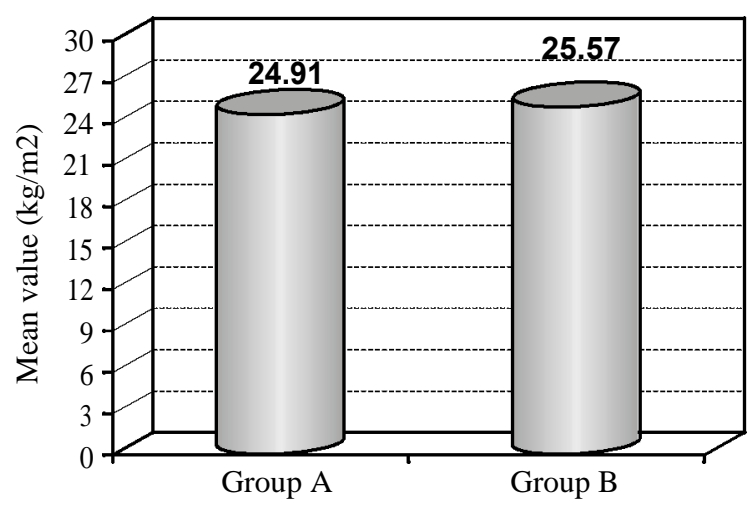

Fig. (4): Mean values of BMI in both groups.
- Comparison of Visual Analogue Scale (VAS) and lumbar Joint ROM (Flexion, extension \& lateral flexion) pre and post treatment between and within groups:

\section{Between group comparison:}

There was no significant difference between group A and group B in all parameters pre treatment $(p>0.05)$. While post treatment there was a significant increase in the lumbar ROM of group A compared with that of group B ( $p>0.05)$. Group A showed significant decrease in VAS compared with that of the group B post treatment $(p<0.01)$.

\section{Within group comparison:}

In group A, there was a statistical significant decrease in the median value of VAS measured at post-treatment when compared with its corresponding value measured at pre-treatment $(p$-value $=$ 0.001 ), there was a statistical significant increase in the mean value of lumber flexion measured at post-treatment when compared with its corresponding value measured at pre-treatment $(p$-value $=$ $0.001) \&$ there was a statistical significant decrease in the mean value of lumber extension and lateral flexion measured at post-treatment when compared with its corresponding value measured at pretreatment $(p$-value $=0.001)$.

In group $B$, there was a statistical significant decrease in the median value of VAS measured at post-treatment when compared with its corresponding value measured at pre-treatment $(p$-value $=$ 0.001 ), there was no statistical significant difference between the mean value of lumber flexion and extension measured at pre-treatmentand its corresponding value measured at post-treatment ( $p$ value $=0.277) \&$ there was a statistical significant decrease in the mean value of lumber lateral flexion measured at post-treatment when compared with its corresponding value measured at pre-treatment $(p$-value $=0.001)$.

Table (2): Intra and inter-group comparison between median values of VAS in the two studied groups measured pre- and post-treatment.

\begin{tabular}{lcccl}
\hline & $\begin{array}{c}\text { Group A } \\
(\mathrm{n}=15)\end{array}$ & $\begin{array}{c}\text { Group B } \\
(\mathrm{n}=15)\end{array}$ & Z\# value & $p$-value \\
\hline Pre-treatment & $3.0(2.0-4.0)$ & $3.0(2.0-4.0)$ & -1.101 & $0.271(\mathrm{NS})$ \\
Post-treatment & $1.0(0.0-2.0)$ & $2.0(1.0-3.0)$ & -3.953 & $0.001(\mathrm{~S})$ \\
Z\#\# value & -3.487 & -2.887 & & \\
$p$-value & $0.001(\mathrm{~S})$ & $0.001(\mathrm{~S})$ & & \\
\hline
\end{tabular}

Data are expressed as median (minimum-maximum).

$\mathrm{NS}=p>0.05=$ Not significant.

$\mathrm{S}=p<0.05=$ Significant.

Z\# = Mann Whitney test.

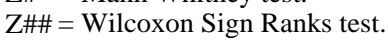




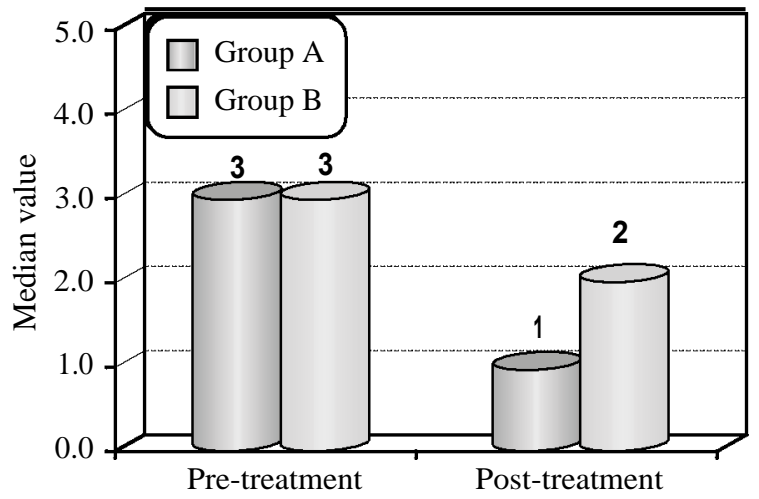

Fig. (5): Median values of VAS in the two studied groups measured pre- and post-treatment.

Table (3): Intra and inter-group comparison between mean values of lumber flexion in the two studied groups measured pre- and post-treatment.

\begin{tabular}{lllll}
\hline & $\begin{array}{c}\text { Group A } \\
(\mathrm{n}=25)\end{array}$ & $\begin{array}{c}\text { Group B } \\
(\mathrm{n}=25)\end{array}$ & F-value & $p$-value \\
\hline Pre-treatment & $3.20 \pm 0.84$ & $3.70 \pm 0.94$ & 2.354 & $0.136(\mathrm{NS})$ \\
Post-treatment & $6.10 \pm 0.63$ & $3.93 \pm 0.99$ & 96.086 & $0.001(\mathrm{~S})$ \\
Mean difference & 2.90 & 0.23 & & \\
$\%$ change & $90.63 \uparrow \uparrow$ & $6.22 \uparrow \uparrow$ & & \\
$p$-value & $0.001(\mathrm{~S})$ & $0.277(\mathrm{NS})$ & & \\
\hline
\end{tabular}

Data are expressed as median (minimum-maximum).

$\mathrm{NS}=p>0.05=$ Not significant.

$\mathrm{S}=p<0.05=$ Significant.

$\mathrm{F}=$ ANOCA test.

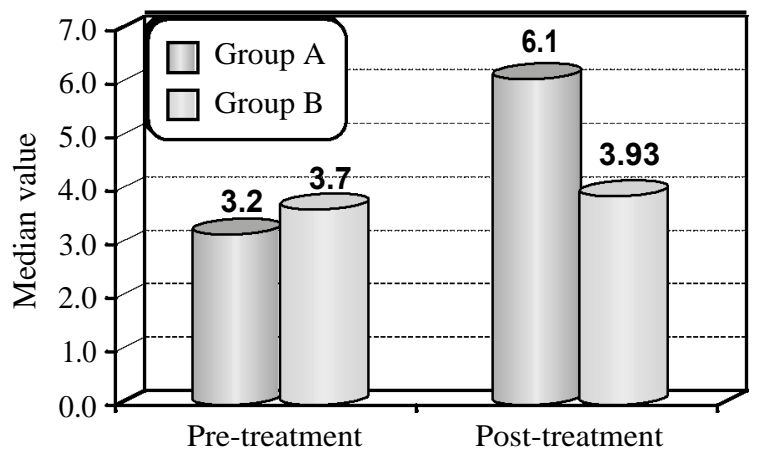

Fig. (6): Median values of lumber flexion in the two studied groups measured pre- and post-treatment.

Table (4): Intra and inter-group comparison between mean values of lumber extension in the two studied groups measured pre- and post-treatment.

\begin{tabular}{lllll}
\hline & $\begin{array}{c}\text { Group A } \\
(\mathrm{n}=15)\end{array}$ & $\begin{array}{c}\text { Group B } \\
(\mathrm{n}=15)\end{array}$ & F-value & $p$-value \\
\hline Pre-treatment & $13.05 \pm 0.59$ & $13.20 \pm 0.56$ & 0.533 & $0.471(\mathrm{NS})$ \\
Post-treatment & $11.60 \pm 0.57$ & $13.13 \pm 0.52$ & 71.643 & $0.001(\mathrm{~S})$ \\
Mean difference & 1.45 & 0.07 & & \\
$\%$ change & $11.11 \downarrow \downarrow$ & $0.53 \downarrow \downarrow$ & & \\
$p$-value & $0.001(\mathrm{~S})$ & $0.499(\mathrm{NS})$ & & \\
\hline
\end{tabular}

Data are expressed as median (minimum-maximum).

$\mathrm{NS}=p>0.05=$ Not significant.

$\mathrm{S}=p<0.05=$ Significant.

$\mathrm{F}=$ ANOCA test.

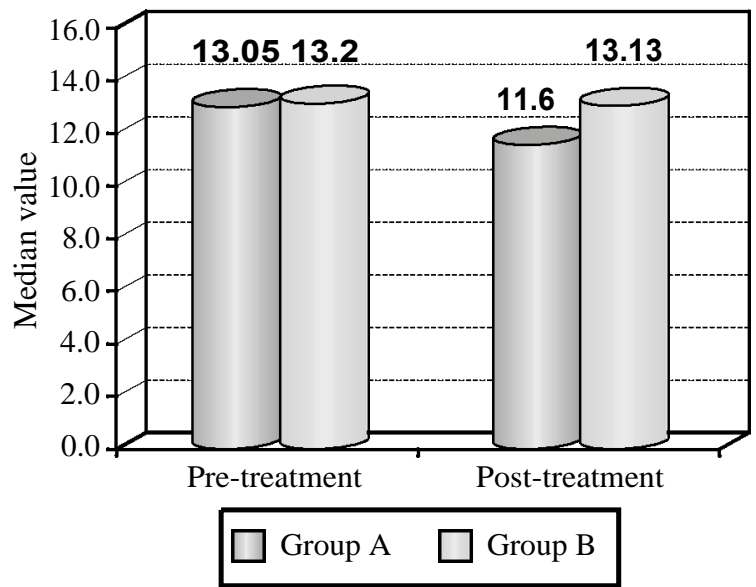

Fig. (7): Median values of lumber extension in the two studied groups measured pre- and post-treatment.

Table (5): Intra and inter-group comparison between mean values of lumber lumbar lateral flexion in the two studied groups measured pre- and post-treatment.

\begin{tabular}{lllll}
\hline & $\begin{array}{c}\text { Group A } \\
(\mathrm{n}=15)\end{array}$ & $\begin{array}{c}\text { Group B } \\
(\mathrm{n}=15)\end{array}$ & F-value & $p$-value \\
\hline Pre-treatment & $30.67 \pm 1.45$ & $30.87 \pm 1.03$ & 0.191 & $0.666(\mathrm{NS})$ \\
Post-treatment & $28.20 \pm 1.01$ & $30.33 \pm 0.92$ & 128.328 & $0.001(\mathrm{~S})$ \\
Mean difference & 2.47 & 0.54 & & \\
$\%$ change & $8.05 \downarrow \downarrow$ & $1.75 \downarrow \downarrow$ & & \\
$p$-value & $0.001(\mathrm{~S})$ & $0.001(\mathrm{~S})$ & & \\
\hline
\end{tabular}

Data are expressed as median (minimum-maximum). NS $=p>0.05=$ Not significant.

$\mathrm{S}=p<0.05=$ Significant.

$\mathrm{F}=$ ANOCA test.

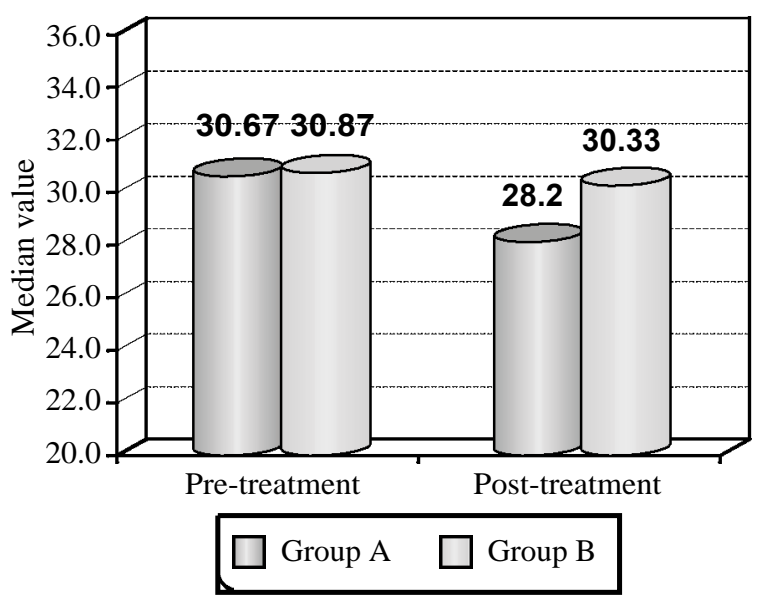

Fig. (8): Median values of lumbar lateral flexion in the two studied groups measured pre- and post-treatment.

\section{Discussion}

Low back pain (LBP) and/or pelvic girdle pain (PGP) has a prevalence of $20-90 \%$ in the pregnant population, while a small number of women may suffer from a combination of both pains $[\mathbf{1 4 , 1 5 ]}$ While PGP is typically more common and intense 
during pregnancy, LBP is more intense and common in the postpartum period [16].

In fact, up to $75 \%$ of women who suffer from pregnancy-related back pain may continue to have pain after giving birth $[\mathbf{1 7 , 1 8}]$.

The purpose of this study was to compare between the effect of taping and acupressure on postnatal low back pain. Thirty women suffering from postpartum low back pain were enrolled in the study, classified into 2 groups Group (A): 15 women used kinesio taping technique three times per week for 4 weeks, Group (B): 15 women received acupressure therapy three times per week for 4 weeks. All women were evaluated for pain severity and lumbar mobility.

These results are in consistence with the findings of Paoloni et al., [19] who found that kinesio taping (KT) leads to pain relief and lumbar muscle function normalization shortly after its application.

The results of this study agreed with those of Alexander et al., [20] who found that stimulating these points by using either pressure or needles causes a measurable release of endorphins into the blood. The activation of small myelinated nerve fibers sends impulses into the spinal cord, midbrain, pituitary and hypothalamus, various endorphins block incoming pain information through the release of serotonin, norepinephrine and possibly aminobutyric acid.

In the present study, the lumbar mobility: Lumbar flexion ROM mean value pre and post treatment (after 1 month) for group (A): There was a statistical significant increase in the median value of lumber flexion measured at post-treatment when compared with its corresponding value measured at pretreatment $(p$-value $=0.001)$, while in group $\mathrm{B}$, there was no statistical significant difference between the mean value of lumber flexion measured at pre-treatment and its corresponding value measured at post-treatment $(p$-value $=0.277)$.

These results are in consistence with the findings of Yoshida and Kahanov, [21] who determined that KT applied over the lower trunk may increase active lower trunk flexion range of motion.

In the present study, the lumbar extension ROM mean value for group (A): There was a statistical significant decrease in the mean value of lumber extension measured at post-treatment when compared with its corresponding value measured at pre-treatment $(p$-value $=0.001)$, while in group B, there was no statistical significant difference be- tween the mean value of lumber extension measured at pre-treatment and its corresponding value measured at post-treatment $(p$-value $=0.499)$.

Yoshida and Kahanov, [21] disagreed with these results as they determined that kinesio taping applied over the lower trunk has no effect for lumbar extension range of motion.

In the present study, the lumbar side bending ROM mean value pre and post treatment (after 1 month) for group (A), there was a statistical significant decrease in the mean value of lumber LLF measured at post-treatment when compared with its corresponding value measured at pre-treatment $(p$-value $=0.001)$, also in group $\mathrm{B}$, there was a statistical significant decrease in the mean value of lumber LLF measured at post-treatment when compared with its corresponding value measured at pre-treatment $(p$-value $=0.001)$.

These results are consistent with Yoshida and Kahano, [21] who determined that KT applied over the lower trunk may increase active lower trunk flexion range of motion. But disagreed on that, no effect was identified for extension and lateral bending, They concluded that further investigation on the effects of KT is warranted.

\section{Conclusion:}

From this study, the previous results, it was concluded that kinesio taping is more effective in decreasing pain severity and increasing lumbar mobility (lumbar flexion, extension and lateral bending) than acupressure.

So, kinesio taping can be used as an effective method in treatment of postnatal low back pain.

\section{References}

1- SHARMA P.: "Post-natal period: Midwifery and obstetrical nursing". Gennext Publication: India, 1 st Ed: Ch. (5): p103, 2010.

2- GUNN J., SOUTHERN D., CHONDROS P., THOMSON P. and ROBERTSON K.: "Guidelines for assessing postnatal Problems: introducing evidence-based guidelines in Australian general practice". Family Practice, 20: 382389, 2003.

3- OSTGAARD H.C., DIEEN V.J., WUISMAN P.I., MENS J.M., UEGAKI K., MEIJER O.G. and WU W.H.: "Pregnancy-related pelvic girdle pain: Terminology, clinical presentation, and prevalence". European Spine Journal, 13: 575-589, 2004.

4- NILSSON W.L., HOLM K., OIJERSTEDT R. and HARMS R.K.: "Effect of three different physical therapy treatments on pain and activity in pregnant women with pelvic girdle pain: A randomized clinical trial with 3,6 , and 12 months follow-up postpartum". Spine, 30 (8): 850856,2005 . 
5- RUSSELL R., GROVES P., TAUB N., O'DOWD J. and REYNOLDS F.: "Assessing long term backache after childbirth". BMJ, 306: 1299-303, 1993.

6- PAUL J.A., VAN D.I. and FRINGER-DRESEN M.H.: "Work load and musculoskeletal complaints during pregnancy". Scand J. Work Environ Health, 20: 153-9, 1994.

7- OZGEN S.U., OZGEN S., CELIKER R., TORAMAN F. and BAYKAN N.: "Back pain after labor under epidural". Analgesia. M. E. J. Anesth., 22 (4): 429-432, 2014.

8- SANDHU K. and DASH H.H.: "Anesthesia related neurological complication". Indian Journal of Anesthesia, 48 (6): 439-445, 2004

9- MacARTHUR C., LEWIS M., KNOX E.G. and CRAWFORD J.S.: "Epidural anesthesia and long term backache after childbirth". BMJ, Vol. 301: 9-12, 1990.

10- KIM TROBEC, and MELITA PERS OLJA: "Efficacy of Kinesio Taping in reducing low back pain: A comprehensive review". Journal of Health Sciences, 7 (1): 1-8, 2017.

11- MAIA1 E.L.M., MATOS1 F.R., BEUX1 R.K., SILVEIRA1 T.S., DUARTE2 C.P., CARDOSO3 C.C., DAITX4 R.B. and DÖHNERT4 M.B.: "Kinesio Tape Associated with Lumbopelvic Stability Exercises in Chronic Nonradicular Lumbar Pai", 25 (2): 1-14, 2018.

12- CHOU R. and HUFFMAN L.H.: "Guideline for the Evaluation and Management of Low Back Pain Evidence Review". American Pain Society, 2007.

13- KASE K., WALLIS J. and KASE T.: "Clinical Therapeutic applications of The Kinesio Taping Method", 84: 12-84, 2003.

14- MALMQVIST S., KJAERMANN I., ANDERSEN K., ØKLAND I., BRØNNICK K. et al.: "Prevalence of low back and pelvic pain during pregnancy in a Norwegian population". J. Manipulative Physiol. Ther., 35: 272-278, 2012.
15-KATONIS P., KAMPOUROGLOU A., AGGELOPOULOS A., KAKAVELAKIS K., LYKOUDIS S., et al.: "Pregnancy-related low back pain". Hippokratia, 15: 205-210, 2011.

16- OSTGAARD H.C., ROOS-HANSSON E. and ZETHERSTRÖM G.: "Regression of back and posterior pelvic pain after pregnancy". Spine (Phila Pa 1976), 21 : 27772780,1996

17- BASTIAENEN C.H., de BIE R.A., VLAEYEN J.W., GOOSSENS M.E., LEFFERS P., et al.: "Long-term effectiveness and costs of a brief self-management intervention in women with pregnancy-related low back pain after delivery". BMC Pregnancy Childbirth, 8: 19, 2008.

18- GUTKE A., LUNDBERG M., ÖSTGAARD H.C. and Öberg, B.: "Impact of postpartum lumbopelvic pain on disability, pain intensity, health-related quality of life, activity level, kinesiophobia, and depressive symptoms". Eur. Spine J., 20: 440-448, 2011.

19- PAOLONI M., BERNETTI A., FRATOCCHI G., MANGONE M., PARRINELLO L.. DEL PILAR COOPER L., SESTO L., DI SANTE L. and SANTILLI V.: "Kinesio tap ing applied to lumbar muscles influences clinical and electromyographic characteristics in chronic low back pain patients". Eur. J. Phys. Rehabil Med., 47 (2): 237 244, 2011.

20- ALEXANDER K., THOMAS M.D., MANFRED G. and KLAUS H.: "Prehospital Analgesia with Acupressure in Victims of Minor Trauma A Prospective, Randomized, Double-Blinded Trial". Anesth. Analg., (95): 723-727, 2002.

21- YOSHIDA A. and KAHANOV L.: "The effect of kinesio taping on lower trunk range of motions". Research in Sports Medicine, April 15 (2): 103 112, 2007. 


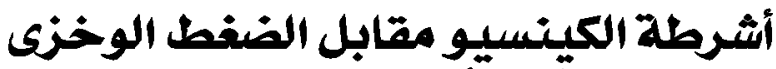

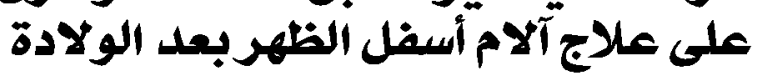

مقدمة: يعتبر ألم أسفل الظهر بعد الولادة من المشاكل التى تعانى منها الآم بعد الولادة وهناك العديد من الأبحاث لمعالجة آلام أسفل الظهر بعد الولادة.

الهدف من الدراسة: أن الهلف من هذه الدراسة هو المقارنة بين تأثير أشرطة الكينسيو مقابل الضفط الوخزى على علاج آلام أسفل الظهر بعد الولادة.

وقد أجريت هذه الدراسة فى العيادات الخارجية لأمراض النساء والتوإيد بمستثفى الثُرطة بالقاهرة الجديدة ومستشفى الثرطة بمدينة

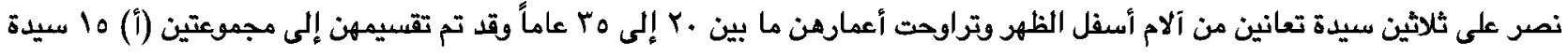

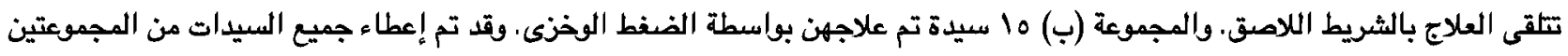

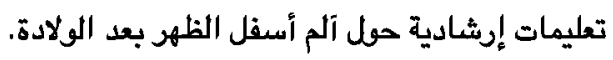

$$
\text { - وقد تضمنت القياسات: }
$$

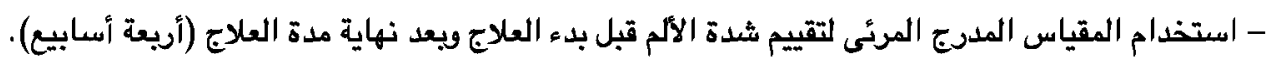

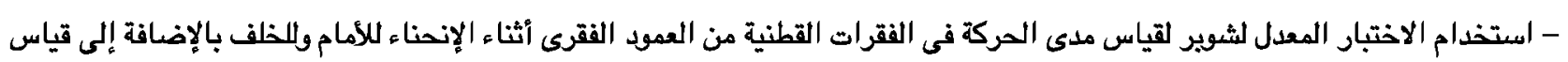
مدى الحركة أثناء الإنحناء للجانب الأيمن والأيسر قبل بدء العرك العلاج وبعد نهاية مدة العلاج (أربعة أسابيع).

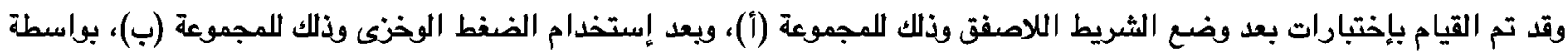

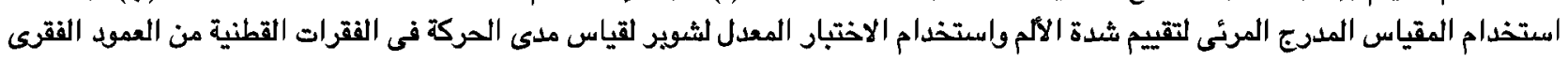

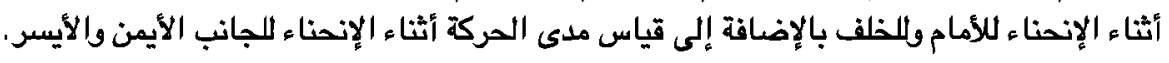
النتائج: أظهرت النتائج ما يلى: كان هناك اختلاف ذو دلالة إحصائية واضحة عند استخدام الشريط اللاصق بالمقارنة مع الضغط الوخزى على أسفل الظهر بعد الولادة. التخلاصة: استخدام الشريط اللاصق بالمقارنة مع الضفط الوخزى له تأثير أكثر فاعلية في علاج آلام أسفل الظهر بعد الولادة ويمكن

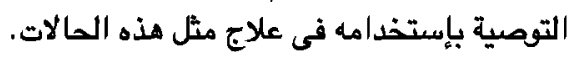

